\title{
Повышение технических характеристик импульсных терагерцовых спектрометров с помощью микроструктурных квазиоптических фильтров нижних частот
}

\author{
А.А. Рыбак ${ }^{1,2)}$, Н.А. Николаев ${ }^{1)}$, С.А. Кузнецов ${ }^{2,3)}$ \\ ${ }^{1}$ Институт автоматики и электрометрии СО РАН, Новосибирск, \\ 630090, пр. Академика Коптюга, 1 \\ ${ }^{2}$ Новосибирский государственный университет, Новосибирск, 630090, Пирогова, 1 \\ ${ }^{3}$ Новосибирский филиал Института физики полупроводников им. А.В. Ржанова СО РАН "КТИПМ", \\ Новосибирск, 630090, пр. Академика Лаврентьева, 2/1 \\ тел:+7 (383) 330-84-53, эл. nочта: rybak.alinka2011@yandex.ru
}

DOI 10.34077/RCSP2019-153

Импульсная терагерцовая (ТГц) спектроскопия (в зарубежной литературе Time-Domain Spectroscopy, TDS) - один из быстроразвивающихся и перспективных методов исследования диэлектрических свойств материалов и структур, в том числе динамики и кинетики процессов релаксации фотовозбужденных носителей зарядов на субпикосекундном разрешении. Типичный сигнал спектрометра представляет собой однопериодное колебание электромагнитного поля короткий импульс длительностью около 1 пс, несущий широкий спектр частот $0,1-3$ ТГц. Принцип спектроскопии основан на регистрации отклика среды на данное импульсное воздействие, а её особенностью является непосредственное измерение временной формы напряженности электрического поля, которое несет информацию об амплитуде и фазе. Детектирование сигнала осуществляется аналогово-цифровым преобразованием, а дальнейшая обработка происходит в цифровом виде, включая преобразование Фурье временной формы сигнала. Таким образом, для данного вида спектроскопии справедлива теорема Котельникова, в частности, детектирование сигнала с полосой до 3 ТГц осуществляется с временным шагом не более 150 фс.

Отметим, что при ТГц измерениях существует ряд задач, в которых информативной является лишь низкочастотная область спектра исследуемого объекта $(<0,5$ ТГц). В данной работе нами предлагается подход, повышающий технические характеристики импульсных ТГц спектрометров при низкочастотных измерениях, который основан на применении фильтров нижних частот (ФНЧ) для сужения полосы терагерцового сигнала. Это позволяет увеличить шаг семплирования, а следовательно, значительно сократить общее время сканирования, или увеличить во столько же раз время усреднения сигнала в каждой точке при сохранении общего времени измерения.

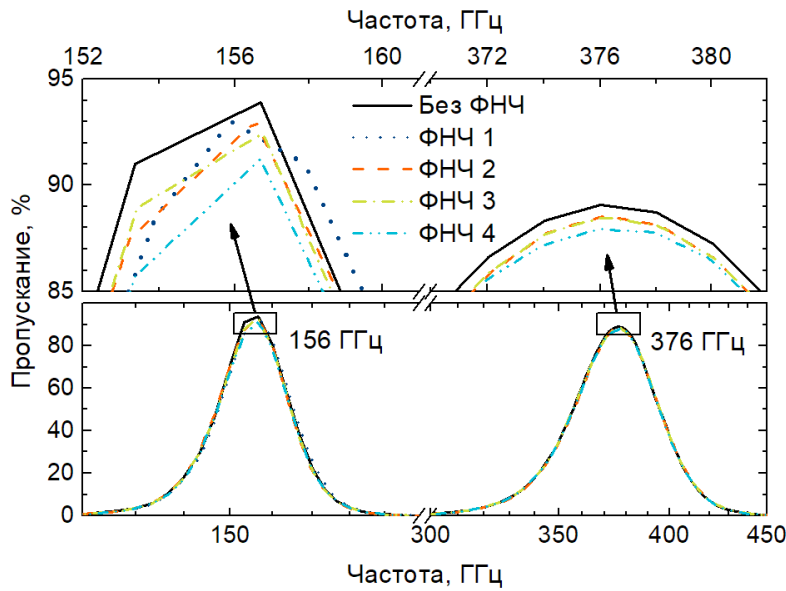

Предложенный подход апробирован на импульном ТГц спектрометре (ЦКП «Спектроскопия и оптика», ИАиЭ СО РАН [1]). В качестве эталонных образцов использовались полосовые пропускающие фильтры (ППФ) с центральными частотами пропускания 156 и 376 ГГц, спектры которых дополнительно исследовались на ЛОВ-спектрометре. В качестве ФНЧ были выбраны фильтры с частотами среза, ГГц: 250 (№1), 500 (№2), 1000 (№3), 1500 (№4). Bce фильтры были изготовлены с использованием технологии многослойных частотно-избирательных поверхностей [2]. В соответствии с теоремой семплирования для измерений выбран следующий шаг, фс: 125 (без ФНЧ), 1500 (ФНЧ 1); 750 (ФНЧ 2); 375 (ФНЧ 3); 250 (ФНЧ 4). Диапазон семплирования составил 120 пс. В результате показано, хорошее согласие полученных спектров (см. рис.). Достигнуто уменьшение времени сканирования до 12 раз при сохранении точности определения амплитуды ППФ 156 ГГц в пределах 4\% и ППФ 376 ГГц в переделах 1\%. Такая разница может быть объяснена более заметной дифракцией длинноволнового излучения в окрестности 156 ГГц.

\section{Лumepamypa}

[1] Nikolaev N., Kuznetsov S., Beruete M. //Proc. 48th European Microwave Conf. (EuMC 2018), Madrid, Spain, Sep. 25-27, 2018, Article no. 18283252, P. 420-423.

[2] S. A. Kuznetsov et al. //Proc. 44th European Microwave Conf. (EuMC 2014), Rome, Italy, Oct. 6-9, 2014, Article no. 6986576, P. 881-884. 